\title{
Rational Design of Efficient Semiconductor-based Photocatalysts via Microdroplets: A Review ${ }^{\dagger}$
}

\author{
Xiang He and Wei-Ning Wang* \\ ${ }^{1}$ Department of Mechanical and Nuclear Engineering, Virginia Commonwealth University, US
}

\begin{abstract}
Semiconductor-based photocatalysis is regarded as an effective approach to harness solar energy to address the critical energy and environmental issues, such as fossil fuel shortage and climate change. The overall efficiency of the semiconductor-based photocatalysts can be further improved by creating nanocomposites with the incorporation of other functional materials, including metals, graphene, and metal-organic frameworks (MOFs). This critical review highlights the recent progress on the rational design of semiconductor-based photocatalysts via microdroplets, where the synthesis can be completed in a fast and controlled manner. Particular emphasis is given to three typical semiconductor-based composites, including semiconductor heterojunctions, crumpled graphene oxide/semiconductor composites, and MOF/semiconductor composites. The rationale behind the nanocomposite design, photocatalytic performance, and fundamental mechanisms are systematically discussed.
\end{abstract}

Keywords: heterogeneous catalysis, heterojunction, spray pyrolysis, crumpled graphene oxide, $\mathrm{MOFs}, \mathrm{CO}_{2}$ photoreduction

\section{Introduction}

The Earth's surface (i.e., the land and oceans) receives about 89 petawatts $\left(\mathrm{PW}=10^{15} \mathrm{~W}\right)$ of solar energy from the total incoming solar radiation (Tian Y. and Zhao C.Y., 2013). This enormous sustainable energy has stimulated numerous applications, such as solar desalination, solar thermal electricity, and photocatalysis, to mitigate environmental deterioration and energy crisis. Among these strategies, semiconductor-based heterogeneous catalysis by harnessing solar energy, that is, the so-called photocatalysis, has drawn extensive attention since the first demonstration of photocatalytic water splitting by Fujishima and Honda in 1972 (Fujishima A. and Honda K., 1972). The fundamental mechanisms of the semiconductor-based photocatalysis have been widely explored and established by prior studies (Fujishima A. et al., 2008; Hoffmann M.R. et al., 1995; Linsebigler A.L. et al., 1995; Schneider J. et al., 2014). As schematically illustrated in Fig. 1 (Wang H. et al., 2014), a typical process of the semiconductorbased photocatalysis is composed of several steps, including light absorption, charge generation, separation and migration, and redox reactions. Initially, the photons, with

Received 18 May 2018; Accepted 17 July 2018

J-STAGE Advance published online 31 August 2018

Richmond, Virginia 23219, US

* Corresponding author: Wei-Ning Wang;

E-mail: wnwang@vcu.edu

TEL: +1-(804) 827-4306 FAX: +1-(804) 827-7030 energy equal to or exceeding the bandgap energy of the semiconductors, induce the generation and separation of electron-hole $\left(\mathrm{e}^{-}-\mathrm{h}^{+}\right)$pairs, where electrons are excited to the conduction band (CB), leaving holes in the valence band (VB). Subsequently, the electrons and holes migrate to the semiconductor surface and act as reductants and oxidants, respectively. The whole process is completed at very short time scales. Taking $\mathrm{TiO}_{2}$ as an example, the characteristic times for the charge carriers' generation, migration, and interfacial charge transfer are at the time scales of femtoseconds, femtoseconds to picoseconds, and picoseconds to microseconds, respectively (Schneider J. et al., 2014).

The photocatalysis, however, still suffers from low efficiencies, resulting from several factors, including limited light absorption, inefficient molecule adsorption, and fast recombination of photo-induced charge carriers. To enhance the efficiency, a myriad of efforts have been devoted, such as creating photocatalysts by combining semiconductors with other functional materials (e.g., metals, metal oxides, graphene, and metal-organic frameworks (MOFs)). For instance, the formation of semiconductor heterojunctions, such as $\mathrm{CdS} / \mathrm{WO}_{3}$ (Jin J. et al., 2015), $\mathrm{Fe}_{2} \mathrm{O}_{3} / \mathrm{Cu}_{2} \mathrm{O}$ (Wang J.-C. et al., 2015), $\mathrm{CdS} / \mathrm{C}_{3} \mathrm{~N}_{4}$ (Cao S.-W. et al., 2013), $\mathrm{ZnO} / \mathrm{CuO}$ (Wang W.N. et al., 2015), and $\mathrm{TiO}_{2} / \mathrm{Cu}_{2} \mathrm{O}$ (He X. and Wang W.N., 2018), can enhance the light absorption and facilitate the charge separation. The enhanced charge separation can also be achieved by creating the semiconductor/graphene composites (Jiang Y. et al., 


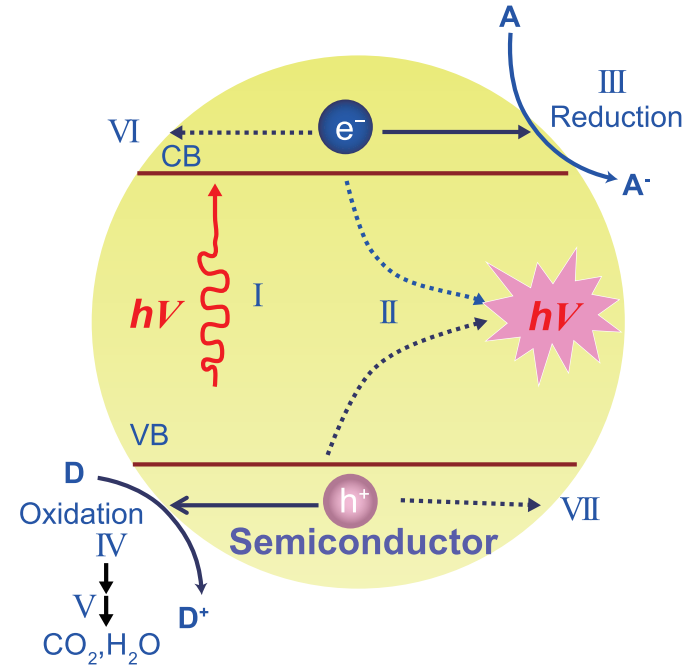

Fig. 1 Schematic illustration of the principle of semiconductor photocatalysis: (I) the formation of charge carriers by a photon; (II) the charge carrier recombination to liberate heat; (III) the initiation of a reductive pathway by a conduction-band electron; (IV) the initiation of an oxidative pathway by a valence-band hole; (V) the further thermal (e.g., hydrolysis or reaction with active oxygen species) and photocatalytic reactions to yield mineralization products; (VI) the trapping of a conduction band electron in a dangling surficial bond; (VII) the trapping of a valenceband hole at the surface of the semiconductor. Reprinted with permission from Ref. (Wang H. et al., 2014). Copyright: (2014) The Royal Society of Chemistry.

2014; Li N. et al., 2011; Nie Y. et al., 2016; Wang W.N. et al., 2014). While the incorporation of MOFs with semiconductors can improve the molecular adsorption (He X. et al., 2017a; He X. et al., 2017b). Given the aforementioned benefits of the formed semiconductor-based composite photocatalysts, a variety of methods have been applied, such as in situ growth (Cao S.-W. et al., 2013; He X. et al., 2017b; Wang D. et al., 2017), and chemical precipitation (Huang H. et al., 2015; Huang L. et al., 2009). It should be noted that, complicated steps and long reaction durations are inevitable in these methods.

On the other hand, a microdroplet-based aerosol process (i.e., the spray process, hereafter) is an alternative approach for the facile and fast synthesis of semiconductorbased photocatalysts. In a typical spray process, microdroplets serve as the reactors, which produce materials with controllable stoichiometry, tunable size, and high crystallinity in a fast manner (Okuyama $\mathrm{K}$. and Wuled Lenggoro I., 2003; Wang W.N. et al., 2011a, 2013), offering lots of opportunities to improve the efficiency of catalysts. Given the growing studies regarding the design of semiconductor-based photocatalysts via microdroplets during the past years, it is of great importance to summarize the progress on this subject, which would promote the future development of photocatalysts and their applications to address energy and environmental issues.
Therefore, a comprehensive review is provided here, covering the basics of the spray processes and the utilization of these processes for the rational design and facile synthesis of efficient photocatalysts, including semiconductor heterojunctions, graphene/semiconductor composites, and MOF/semiconductor composites.

\section{Basics of the spray processes}

A schematic illustration of a representative spray system for the synthesis of nanomaterials is shown in Fig. 2. The system generally comprises of an atomizer (or nebulizer), an aerosol reactor, and a sample collector. In a spray pyrolysis process, the atomizer produces microdroplets from the precursor solution. The microdroplets are then fed through the aerosol reactor (e.g., an electrical furnace, a flame reactor, or a plasma chamber) by the carrier gas, where the solvent evaporation, nucleation, pyrolysis, and crystallization occur to form the final products (Wang W.N. et al., 2011a). In a spray drying process, a colloidal suspension is used as the precursor and the evaporation-induced self-assembly (EISA) of the colloids inside the microdroplets (Boissiere C. et al., 2011; Iskandar F. et al., 2003; Lu Y.F. et al., 1999) is a major step to form the final particles. Finally, the products are collected by the collectors, such as filters and electrostatic precipitators.

Theoretical understanding of mass and heat transfer principles within the microdroplets is of paramount importance to guide the design and synthesis of materials by using the spray process. For example, great attention has been attracted to the design of functional materials via the EISA of nanoparticles within microdroplets by manipulating the solvent evaporation rate of the droplets (Boissiere C. et al., 2011; Iskandar F. et al., 2003; Lu Y.F. et al., 1999; Wang W.N. et al., 2011b). Practically, two key parameters, i.e., the size and temperature of the microdroplets play significant roles in the droplet-to-particle conversion process. Their dependence on time is governed by the equations as shown below:

In continuum regime (i.e., the Knudsen number, $K \mathrm{n}<<1$ ): (Xiong Y. and Kodas T.T., 1993)

$$
\begin{aligned}
& \frac{\mathrm{d} R_{\mathrm{d}}}{\mathrm{d} t}=\frac{D_{\mathrm{v}} \cdot m}{R_{\mathrm{d}} \cdot \rho}\left(n_{\infty}-n_{\mathrm{s}}\right) \\
& \frac{\mathrm{d} T_{\mathrm{d}}}{\mathrm{d} t}=\frac{3}{c_{\mathrm{p}} R_{\mathrm{d}}}\left[H_{\text {vap }} \frac{\mathrm{d} R_{\mathrm{d}}}{\mathrm{d} t}+\frac{k_{\mathrm{a}}}{\rho R_{\mathrm{d}}}\left(T_{\mathrm{c}}-T_{\mathrm{d}}\right)\right]
\end{aligned}
$$

In free molecular regime (i.e., $K n>>1$ ): (Fisenko S.P. et al., 2006)

$$
\frac{\mathrm{d} R_{\mathrm{d}}}{\mathrm{d} t}=\frac{m}{\rho}\left[\frac{p_{\mathrm{v}}}{\sqrt{2 \pi m k T_{\mathrm{c}}}}-\frac{p_{\mathrm{s}}}{\sqrt{2 \pi m k T_{\mathrm{d}}}}\right]
$$

where $R_{\mathrm{d}}$ is the radius of the microdroplet; $t$ is time; $D_{\mathrm{v}}$ 


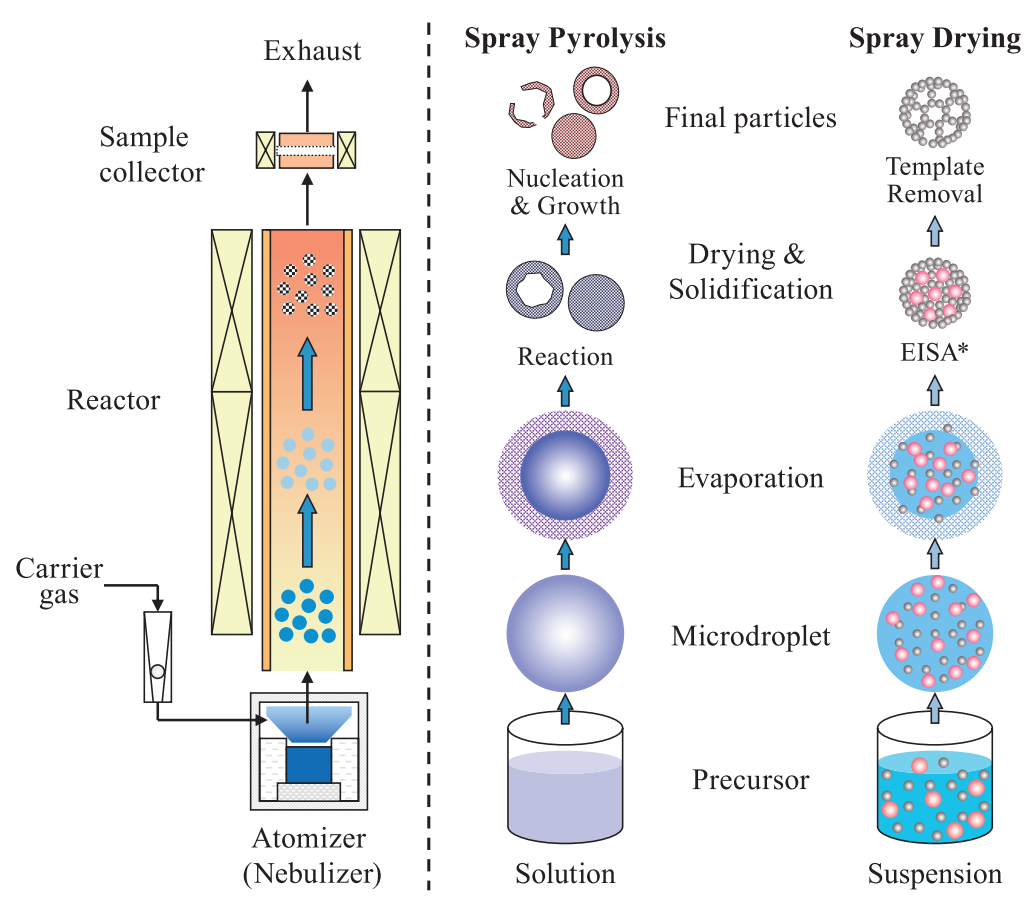

Fig. 2 Schematic illustration of particle synthesis by using the spray route. Left: an example of experimental setup; Right: typical particle formation pathways in spray pyrolysis and spray drying (EISA*: Evaporationinduced self-assembly).

$\frac{\mathrm{d} T_{\mathrm{d}}}{\mathrm{d} t}=\frac{3 \cdot\left[\frac{p_{\mathrm{v}}\left(c_{\mathrm{p}} T_{\mathrm{c}}+H_{\text {vap }}+0.5 k T_{\mathrm{c}}\right)}{\sqrt{m T_{\mathrm{c}}}}-\frac{p_{\mathrm{s}}\left(c_{\mathrm{p}} T_{\mathrm{d}}+H_{\text {vap }}+0.5 k T_{\mathrm{d}}\right)}{\sqrt{m T_{\mathrm{d}}}}+\frac{p T_{\mathrm{c}}\left(c_{\mathrm{p}}+0.5 k\right)}{\sqrt{m T_{\mathrm{c}}}}-\frac{p T_{\mathrm{d}}\left(c_{\mathrm{p}}+0.5 k\right)}{\sqrt{m T_{\mathrm{d}}}}\right]}{c_{\mathrm{p}} \rho R_{\mathrm{d}} \sqrt{2 \pi k}}-\frac{3 T_{\mathrm{d}}}{R_{\mathrm{d}}} \frac{\mathrm{d} R_{\mathrm{d}}}{\mathrm{d} t}$

indicates the diffusion coefficient of solvent vapor in air; $m$ is the molecule mass of the solvent; $\rho$ represents the solvent density; $n_{\infty}$ and $n_{s}$ denote the number densities of solvent molecules at the infinite region and droplet surface, respectively; $T_{\mathrm{d}}$ and $T_{\mathrm{c}}$ are the temperatures of the droplet and the carrier gas, respectively; $c_{\mathrm{p}}$ and $H_{\text {vap }}$ are the specific heat capacity and the specific latent heat of the solvent, respectively; $k_{\mathrm{a}}$ is the heat conductivity of air; $k$ is the Boltzmann constant; $p_{\mathrm{v}}$ and $p_{\mathrm{s}}$ are the partial and saturated pressures of the solvent, respectively; $p$ is the pressure of the carrier gas.

Several precursor and process parameters, including precursor concentration, viscosity, surface tension, droplet size, reactor pressure, temperature, and residence time, can be adjusted to control the properties of the final products (Hidayat D. et al., 2010; Wang W.N. et al., 2011a). For instance, the particle size is highly correlated with the concentration of the precursor solution (Nandiyanto A.B.D. et al., 2008). A governing equation describing this relationship has been developed based on the law of mass conservation (Iskandar F. et al., 2009; Wang W.N. et al., 2007; 2008; 2011b),

$$
D_{\mathrm{p}}=D_{\mathrm{d}}\left(\frac{1}{(1-\varepsilon)} \sum \frac{M_{i} C_{i}}{\rho_{i}}\right)^{\frac{1}{3}}
$$

where the $D_{\mathrm{p}}$ and $D_{\mathrm{d}}$ are the volume mean diameters of the particles and droplets, respectively; $M, C$ and $\rho$ indicate the molecular weight, concentration and density of components in the precursor solution, respectively; $\varepsilon$ represents the porosity of the final particles. In a conventional spray process, a high precursor concentration usually results in a larger particle size.

The pressure also has a significant effect on the properties of the products. At ambient pressure, a conventional spray process follows a one-droplet-to-one-particle (ODOP) principle, which can only generate large particles (i.e., micrometers) due to the limitation of the fine droplet formation (Wang W.N. et al., 2011a). On the other hand, reducing the gas pressure inside the tube furnace reactor (i.e., low-pressure spray process) can significantly fasten the evaporation of the solvents and thus the nucleation of the products (Ashgriz N., 2011; Wang W.N. et al., 2011c). Besides, the low-pressure environment can also limit the aggregation of the products. Therefore, the low-pressure spray process usually produces much smaller particles 
$(\$ 9 \mathrm{\mu th})$, following a one-droplet-to-multiple-particles (QDMP) principle (Ashgriz N., 2011; Hidayat D. et al., 2010; Wang W.N. et al., 2004; 2011a).

\section{Design of photocatalysts via microdroplets}

Based on the fundamental understanding of the spray process, various semiconductor-based photocatalysts have been designed via microdroplets, including semiconductor heterojunctions, graphene/semiconductor composites, and $\mathrm{MOF} / \mathrm{semiconductor}$ composites.

\subsection{Semiconductor heterojunctions}

As mentioned above, the photocatalytic efficiency of semiconductors can be improved by combining the semiconductors with metals or other semiconductors to form heterojunctions, where the photoexcited charge carriers can be efficiently separated and migrated due to the built-in potential (Kittel C., 2005; Somorjai G.A. and Li Y., 2010; Wang D. et al., 2018). The doped metals typically have three functions in the enhancement, including (1) reducing the over-potential as cocatalysts, (2) promoting the separation of charge carriers by creating an electric field near the interface, and (3) increasing light absorption of semiconductors with plasmonic effect $(\mathrm{Qu}$ Y. and Duan X., 2013).

A large number of metal/semiconductor hybrid photocatalysts have been designed by using the spray pyrolysis process. In a typical synthesis procedure (Fig. 3), a mixture of metal ions and semiconductors are atomized to generate microdroplets. The microdroplets then pass through the reactor, where the metal ions are thermally reduced to metals and creating metal/semiconductor composite. For instance, a $\mathrm{Pt} / \mathrm{TiO}_{2}$ hybrid was directly synthesized by a single-step flame spray pyrolysis (Teoh W.Y. et al., 2005). The size of Pt can be adjusted by varying the concentration of the Pt precursor. The results show that the incorporation of $\mathrm{Pt}$ affects not only the crystallinity and surface area of $\mathrm{TiO}_{2}$, but also the overall photocatalytic performance. The flame spray pyrolysis was also applied to synthesize noble metal/ZnO composites (e.g., Au/ $\mathrm{ZnO}$ and $\mathrm{Pt} / \mathrm{ZnO}$ ) in one step (Pawinrat P. et al., 2009).
The noble metals were homogeneously dispersed with average size between 3 and $7 \mathrm{~nm}$. Species of the incorporated noble metals have significant effects on the photocatalytic activity. To be specific, the incorporation of Au can retard the recombination of charge carriers by modifying the Fermi level and trapping electrons. While, in the case of Pt, the electrons might be discharged into electrolytes. Similarly, Haugen et al. applied the spray pyrolysis technique to directly prepare metal (i.e., Ag and $\mathrm{Au}$ ) doped $\mathrm{TiO}_{2}$ photocatalysts (Haugen A.B. et al., 2011). The incorporated metals were found homogeneously distributed within the composite. The as-prepared composites exhibit promising performance in photodegradation of environmental pollutants. Zhao et al. designed $\mathrm{Ag} / \mathrm{TiO}_{2}$ composite photocatalysts by using an ultrasonic spray pyrolysis route (Zhao C. et al., 2012). The as-synthesized composite showed better dispersion of Ag, larger surface area, and thus a six-fold improvement in hydrogen production, in comparison to the one prepared by using the conventional wet-impregnation method. Recently, continuous spray pyrolysis was also applied to synthesize Au/ CdS composite nanoparticles by using cadmium acetate, thiourea and chloroauric acid as the precursors (Kumar N. et al., 2014). The entire process is simple, fast and free of surfactants. The as-prepared hybrid nanoparticles exhibited enhanced photocatalytic efficiency as compared with bare $\mathrm{CdS}$, which was mainly attributed to interfacial charge transfer as evidenced by the photoluminescence study. In addition, a $\mathrm{Pt} / \mathrm{WO}_{3}$ composite photocatalyst was designed by Okuyama's group (Widiyandari H. et al., 2012), where the existence of Pt could be indicated from the stacking-fault in the high resolution transmission electron microscopy (HR-TEM) image. The Pt in the composite acted as a capturer to snatch the photo-induced electrons and thus promotes the separation of the charge carriers. Another example of template-free synthesis of mesoporous $\mathrm{Cu}-\mathrm{TiO}_{2}-\mathrm{SiO}_{2}$ nanocomposites by means of a spray route was demonstrated by Wang et al. (Wang W.N. et al., 2011b). As schematically shown in Fig. 4A, the nanocomposites were prepared from the aqueous suspensions of nanosized $\mathrm{TiO}_{2}$ and $\mathrm{SiO}_{2}$ colloids and copper nitrate via EISA. The particle size, composition, structure, and hence the catalytic performance were tailored by manipulating precursor properties and process parameters.

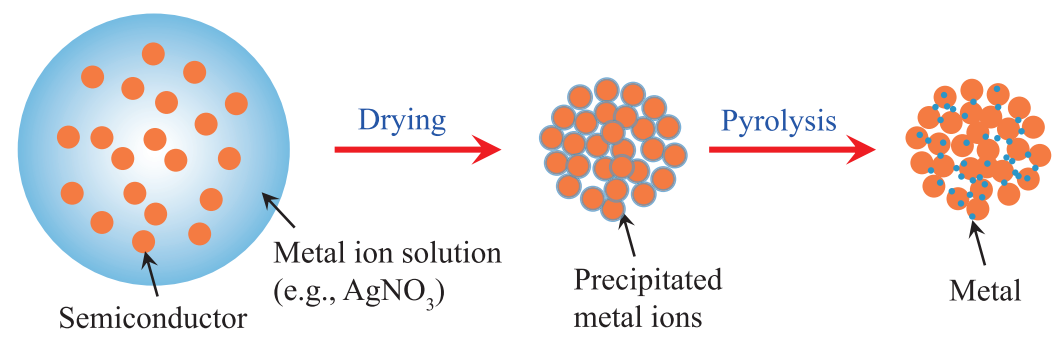

Fig. 3 Schematic illustration of the formation of metal/semiconductor composite. 

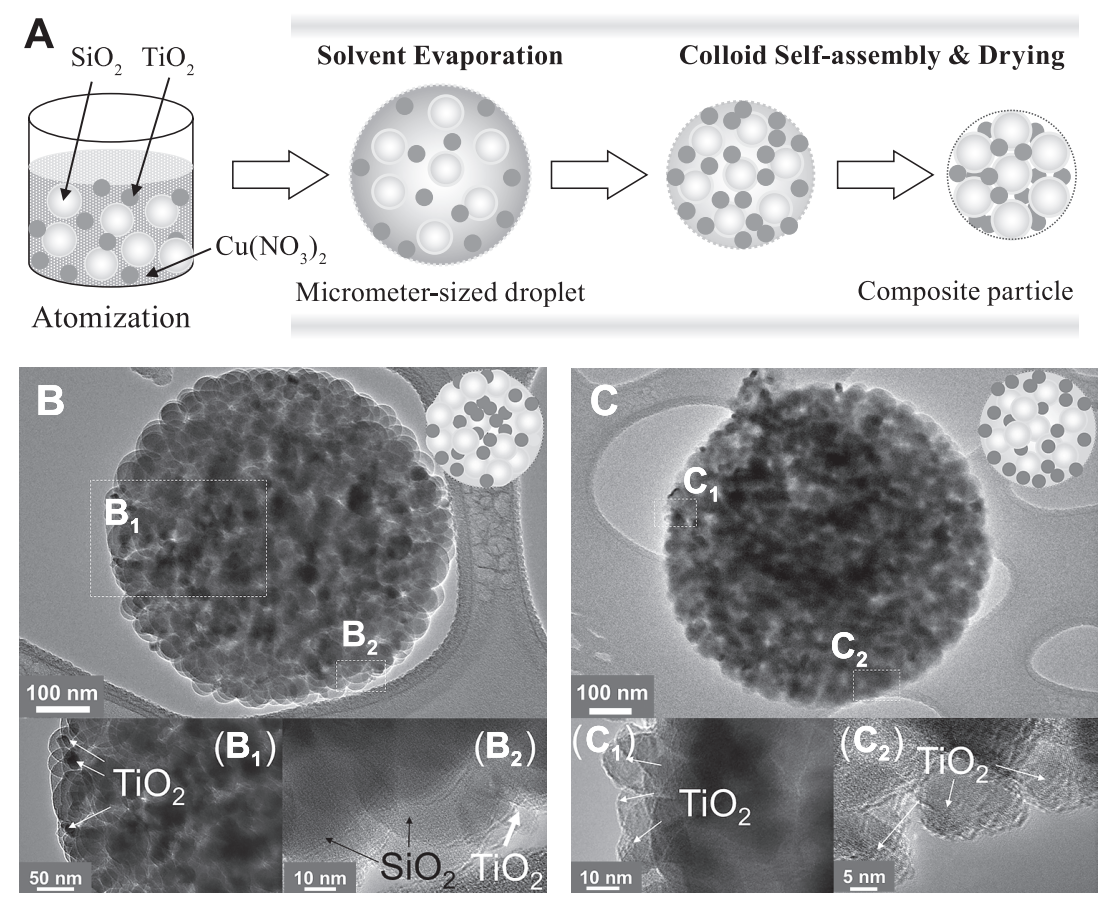

Fig. 4 (A) Possible formation mechanism of $\mathrm{Cu}-\mathrm{TiO}_{2}-\mathrm{SiO}_{2}$ composites; (B) TEM and HR-TEM images of $\mathrm{TiO}_{2}-$ $\mathrm{SiO}_{2}$ composite particles prepared at $400(\mathbf{B})$ and $800{ }^{\circ} \mathrm{C}(\mathbf{C})$. Reprinted with permission from Ref. (Wang W.N. et al., 2011b). Copyright: (2011) The Royal Society of Chemistry.

For example, the reactor temperature was adjusted to control the solvent evaporation rate and hence the movement of $\mathrm{TiO}_{2}$ nanocrystals within the microdroplets. As shown in Figs. 4B and $\mathrm{C}$, more $\mathrm{TiO}_{2}$ nanocrystals can be allocated on the surface of the nanocomposites by increasing the reactor temperature, resulting in enhanced catalytic performance. The self-assembly of the nanoparticles within the microdroplets was considered due to the thermophoretic force (Iskandar F. et al., 2003) and the Brownian motion (Hinds W.C., 1999). The thermophoretic force was created by the temperature gradient at the droplet surface, stemmed from the large heat transfer from droplet surface to gas stream due to the fast solvent evaporation.

Regarding the semiconductor/semiconductor (SS) heterojunctions, the photocatalytic efficiency is mainly facilitated by the migration of charge carriers. The migration pathways at the interfaces are highly dependent on the band structures of the components. Representative types of SS heterojunctions are summarized in Fig. 5, including type-II, p-n, and Z-scheme. Detailed discussion of the charge transfer with different heterojunctions has been comprehensively documented in a recent review (Low J. et al., 2017). Therefore, only a brief explanation for each heterojunction is presented here. In the case of type-II heterojunctions, with the staggered gap, the electrons are confined to the one component semiconductor, while the holes are confined to the other one (Zhou H. et al., 2012). This produces spatially localized charges and promotes separation of charge carriers and thus the photocatalytic

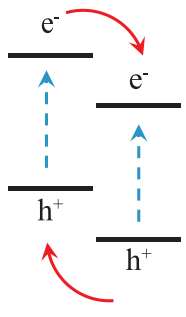

Type-II

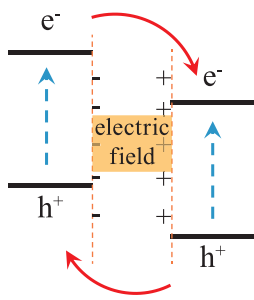

p-n

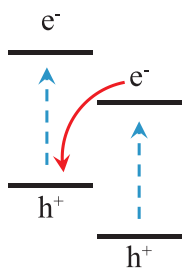

Z-scheme
Fig. 5 Schematic illustration of the charge transfer patterns of typical semiconductor heterojunctions.

efficiency. The migration of the charge carriers can be further accelerated with $p$-n heterojunctions created by p-type and n-type semiconductors. The accelerated charge separation is mainly due to the additional interfacial electric filed, generated by the initial diffusion of electrons and holes (He Z. et al., 2014). It should be noted that, the redox abilities of both type-II and p-n heterojunctions are decreased due to the migration of the charge carriers to lower redox potentials. One solution to this issue is to form Z-scheme heterojunctions, where the photogenerated electrons with lower reduction potential migrate to the other semiconductor and combine with the photogenerated holes with lower oxidation potential. Therefore, not only the separation of the charge carriers is enhanced, but also the charge carriers accumulate at higher redox potentials.

The synthesis of these heterojunctions is generally 
adhievied by using wet-chemistry methods, involving camplicated procedures and sometimes harsh chemicals (e.g., concentrated $\mathrm{HNO}_{3}$ ) (Xu H. et al., 2012). In this regard, a spray process will be an excellent alternative for the fast and facile synthesis of such heterojunctions. For instance, $\mathrm{ZnO} / \mathrm{CeO}_{2}$ nanocomposites prepared by a flame spray pyrolysis were reported by Xiong et al. (Xiong Z. et al., 2017). The nanocomposites exhibited enhanced $\mathrm{CO}_{2}$ photoreduction efficiency, mainly attributed to the existence of heterojunction and the co-existence of $\mathrm{Ce}^{4+} / \mathrm{Ce}^{3+}$ pairs. A porous and spherical $\mathrm{TiO}_{2} / \mathrm{In}_{2} \mathrm{O}_{3}$ composite photocatalyst was prepared by using an ultrasonic sprayassisted route ( $\mathrm{Li} \mathrm{C}$. et al., 2014). The incorporation of small amount of $\operatorname{In}_{2} \mathrm{O}_{3}$ enhanced the light absorption and thus promoted the photocatalytic performance towards water treatment. The results also showed that excessive $\mathrm{In}_{2} \mathrm{O}_{3}$ would serve as the recombination center, which would undermine the photocatalytic performance ( $\mathrm{Li} \mathrm{C}$. et al., 2014). Similarly, porous $\mathrm{TiO}_{2} / \mathrm{WO}_{3}$ microspheres were prepared by using a spray pyrolysis method, where the crystal phase of $\mathrm{WO}_{3}$ played an important role in the photocatalytic efficiency (Arutanti O. et al., 2014; Yang J. et al., 2013). In addition to the particles, film composites can also be prepared. For example, Grbić et al. designed a $\mathrm{TiO}_{2} / \mathrm{WO}_{3}$ film composite with a thickness of $\sim 1 \mu \mathrm{m}$ on a stainless steel foil (Grbić B. et al., 2014). The increase of $\mathrm{WO}_{3}$ contents induced positive shift of $\mathrm{Ti}_{2 \mathrm{p}}$ binding energy, suggesting the $\mathrm{TiO}_{2} / \mathrm{WO}_{3}$ interaction. More evidence about the interaction was obtained from Raman analysis, which demonstrated the minimal substitution of $\mathrm{Ti}$ by $\mathrm{W}$ in the crystal lattice. As a result, the photoinduced charge carriers can be effectively separated, leading to enhanced photocatalytic performance.

\subsection{Crumpled graphene oxide/semiconductor composites}

Graphene is two-dimensional (2D) nanosheet of $\mathrm{sp}^{2}$ hybridized carbon atoms with an extended honeycomb network. The thickness of graphene is ultra-small ( $\sim 0.35 \mathrm{~nm}$ ) (Jiang Y. et al., 2016), while its mechanical, thermal and electrical properties are exceptional, stemming from the long-range $\pi$-conjugation (Allen M.J. et al., 2010; Wang W.N. and He X., 2016). Besides, the unique structure also grants graphene with huge specific surface area $\left(\sim 2600 \mathrm{~m}^{2} / \mathrm{g}\right)$ (Stankovich S. et al., 2006), and extraordinary intrinsic electron mobility $\left(\sim 10^{5} \mathrm{~cm}^{2} /(\mathrm{Vs})\right)$ (Novoselov K.S. et al., 2004), both of which are very appealing properties in photocatalysis processes. When combined with semiconductors, graphene promotes the adsorption of the reactants, and helps to increase the lifetime of charge carriers as sinks.

Typical semiconductors, which have been incorporated with graphene for photocatalysis, include $\mathrm{TiO}_{2}$ (Liang Y. et al., 2010; Pan X. et al., 2012; Perera S.D. et al., 2012; Zhang Y. et al., 2011), $\mathrm{Cu}_{2} \mathrm{O}$ (An X. et al., 2014; Tran P.D. et al., 2012; Zhang D. et al., 2016; Zou W. et al., 2016), $\mathrm{BiVO}_{4}$ (Fu Y. et al., 2011; Ng Y.H. et al., 2010; Sun Y. et al., 2012), $\mathrm{Fe}_{2} \mathrm{O}_{3}$ (Han S. et al., 2014), CdS (Jia L. et al., 2011; Li Q. et al., 2011), CdSe (Oh W.-C. et al., 2011), $\mathrm{MoS}_{2}$ (Chang K. et al., 2014; Min S. and Lu G., 2012), and $\mathrm{C}_{3} \mathrm{~N}_{4}$ (Xiang Q. et al., 2011). With the incorporation of graphene, the overall photocatalytic efficiency has been significantly improved. For instance, $\mathrm{Fe}_{2} \mathrm{O}_{3}$ /graphene composites were fabricated by Han et al. for the photodegradation of Rhodamine B (RhB) (Han S. et al., 2014), where the reaction rate of $\mathrm{Fe}_{2} \mathrm{O}_{3} /$ graphene with an optimal ratio was found to be approximately four times higher than that of bare $\mathrm{Fe}_{2} \mathrm{O}_{3}$. The crucial factor for the improved efficiency is the enhanced charge transfer at the intimate and large contact interfaces.

Due to the hydrophobic nature and difficulties of handling of graphene nanosheets in solutions, the most commonly used precursor for graphene to fabricate graphene/ semiconductor composites is the graphene oxide (GO) synthesized from the modified Hummers' method (Hummers Jr W.S. and Offeman R.E., 1958). Different from graphene, GO have massive oxygenated functional groups at the edges (e.g., carbonyl and carboxyl groups) and on the basal plan (e.g., epoxy and hydroxyl groups). These oxygenated groups enable GO dispersible in aqueous solution, which is a great feature for the further development of graphene-related composites. Whereas, these oxygenated groups also disrupt the electronic structure and break the $\pi$-conjugation of the pristine graphene sheets. As a result, the conductivity of the sheets decreased dramatically after the oxygenated functionalization. In order to restore to conductivity of the sheets, reduction process is necessary after the combination of GO and semiconductors. Thus, a more accurate term for the as-prepared composites should be reduced graphene oxide (RGO)/ semiconductor photocatalysts.

Despite the remarkable properties, graphene or RGO sheets have an intrinsic problem, that is, they have a strong tendency to restack and aggregate due to the van der Waals attraction, which would significantly reduce the surface area and compromise the conductivity (Wang W.N. and He X., 2016). As pointed out by Yang et al. (Yang M.-Q. et al., 2014), because of the aggregation, the so-called semiconductor/graphene composites, under some circumstances, are essentially the same as the other semiconductor-carbon (e.g., fullerenes and carbon nanotubes) counterparts. Preventing the graphene or RGO sheets from aggregation is the key, which, however, is hardly achieved by using conventional methods. On the other hand, the spray process provides a promising strategy to address this issue by creating crumpled graphene balls (Chen Y. et al., 2018; El Rouby W.M.A., 2015; Gao 


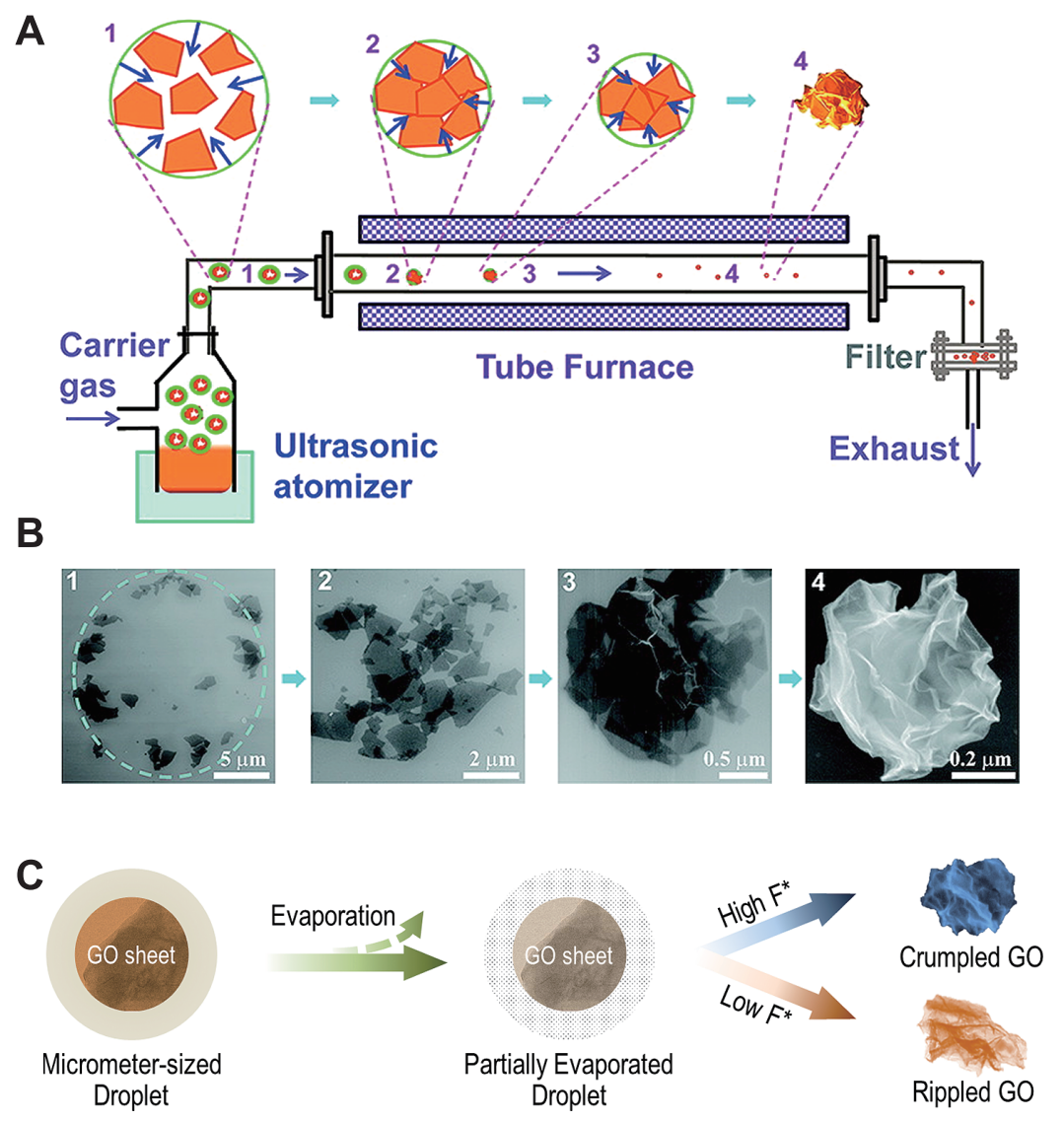

Fig. 6 Particles of crumpled GO sheets by rapid isotropic compression in evaporating aerosol droplets. (A) Schematic drawings illustrating the experimental setup and the evaporation-induced crumpling process. Aerosol droplets containing GO sheets were nebulized and rapidly evaporated by passing through a preheated tube furnace. (B) SEM images of four samples collected along the flying pathway from spots 1 to 4 showing the typical morphologies of deposited GO evolving from (B1) sparse sheets in a "coffee-ring" pattern, (B2) clustered and tiled sheets, (B3) aggregated sheets with extensive wrinkles, to (B4) the final 3D crumpled, ball-like particle. Reprinted with permission from Ref. (Luo J. et al., 2011). Copyright: (2011) American Chemical Society. (C) The possible formation mechanism of crumpled GO (F*: crumpling force). Reprinted with permission from Ref. (Wang W.N. et al., 2012). Copyright: (2012) American Chemical Society.

Z. et al., 2018; Luo J. et al., 2011; Ma X. et al., 2012; 2013; Mao B.S. et al., 2014; Mao S. et al., 2012; Wang W.N. et al., 2012; Zangmeister C.D. et al., 2012). During the solvent evaporation process, the $2 \mathrm{D}$ GO sheets inside the microdroplets will be crumpled into three dimensional (3D) spheres (i.e., crumpled graphene oxide, CGO) (Figs. 6A and $\mathbf{B})$ by the confinement force resulting from the evaporation (Fig. 6C) (Wang W.N. et al., 2012). The unique crumpled structure enables CGO aggregation-resistant (Luo J. et al., 2011), while still maintains a high surface area (over $1500 \mathrm{~m}^{2} / \mathrm{g}$ ), $58.6 \%$ of the original value (Cranford S.W. and Buehler M.J., 2011; El Rouby W.M.A., 2015), which offers stable anchoring sites for the semiconductor nanocrystals. One additional benefit of the spray process is that, the GO can simultaneously be thermally reduced during the spray process, providing CGO with desirable electrical conductivity.

Given all these advantages mentioned above, numerous studies have been carried out to synthesize the $\mathrm{CGO} /$ semiconductor composite photocatalysts (Carraro F. et al., 2015; Jiang Y. et al., 2014; Nie Y. et al., 2016; Wang W.N. et al., 2014). For instance, a spray approach was applied by Wang et al. to produce $\mathrm{CGO} / \mathrm{TiO}_{2}$ composites (Fig. 7A), where $\mathrm{TiO}_{2}$ nanoparticles were encapsulated in the crumpled structure (Wang W.N. et al., 2014). The as-prepared composite demonstrated improved $\mathrm{CO}_{2}$ photoreduction efficiency, and the mechanism was found to be the facilitated charge carrier separation induced by charge trapping ability of CGO. Besides, the CGO can also be amine functionalized to facilitate adsorption of $\mathrm{CO}_{2}$, which would further enhance the $\mathrm{CO}_{2}$ photoreduction efficiency (Nie Y. et al., 2016). In addition, a CGO/ CoO hybrid catalyst (Fig. 7B) was designed with the similar strategy (Mao S. et al., 2014). Furthermore, Carraro et al. used a spray approach to fabricate an N-doped CGO/ $\mathrm{MoS}_{2}$ hybrid (Fig. 7C) in a fast and high-yield manner 

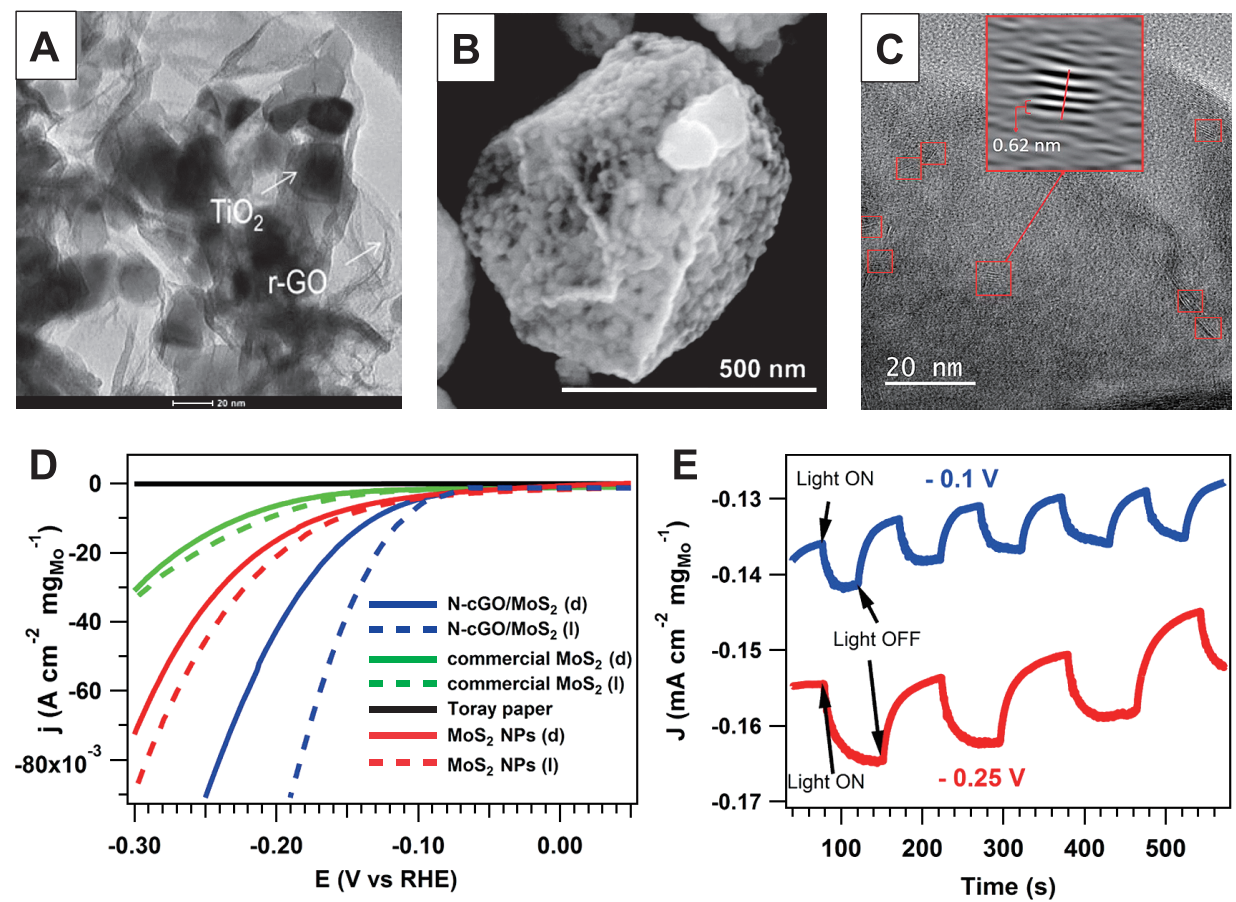

Fig. 7 (A) TEM images of a $\mathrm{CGO} / \mathrm{TiO}_{2}$ composite. Reprinted with permission from Ref. (Wang W.N. et al., 2014). Copyright: (2014) Mary Ann Liebert, Inc. (B) SEM image of a CGO-CoO nanocrystal. Reprinted with permission from Ref. (Mao S. et al., 2014). Copyright: (2014) The Royal Society of Chemistry. (C) HRTEM micrograph of $\mathrm{N}-\mathrm{CGO} / \mathrm{MoS}_{2}$ nanohybrids presenting $\mathrm{MoS}_{2} \mathrm{NPs}$ highlighted by red squares. (D) Polarization curves (not iR corrected) in dark (E) J-t curves under light (ON) and dark (OFF) conditions at -0.1 and $-0.25 \mathrm{~V}$ vs RHE and room temperature for $\mathrm{N}-\mathrm{CGO} / \mathrm{MoS}_{2}$. Reprinted with permission from Ref. (Carraro F. et al., 2015). Copyright: (2015) American Chemical Society.

(Carraro F. et al., 2015), where the existence of N-doped CGO significantly enhanced photoelectrochemical production of hydrogen. The improved efficiency is mainly due to the enhanced charge carrier separation, as evidenced by the fact that $\mathrm{N}$-doped $\mathrm{CGO} / \mathrm{MoS}_{2}$ hybrid has a much higher current density (Figs. 7D and E) compared with bare $\mathrm{MoS}_{2}$ (Carraro F. et al., 2015). Materials, other than semiconductor photocatalysts, can also be supplemented in the crumpled structure to obtain additional functions. For example, Jiang et al. designed a ternary

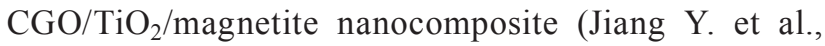
2014), which not only exhibited enhanced photocatalytic ability (20 times of the bare $\mathrm{TiO}_{2}$ ), but also allowed easy recycle and reuse.

\subsection{MOF/semiconductor composites}

As a new class of porous materials, MOFs have attracted intense attention during recent years. MOFs are composed of metal cations and organic ligands (Fig. 8A (Lee Y.-R. et al., 2013)), and exhibit exceptional properties, including large surface area, high porosity and tunable structure. Schematic illustration of typical MOFs is shown in Fig. 8B (Dey C. et al., 2014), including HKUST-1 (HKUST: Hong Kong University of Science and Technology), MIL-101 (MIL: Material of Institute
Lavoisier), and MOF-5. The occurrence of MOFs provides new opportunities to address the long-standing issues in semiconductor-based photocatalysis processes, including but not limited to the deficient gas adsorption, fast recombination of charge carriers, and poor molecule activation. To be specific, when incorporated with semiconductors, MOFs can help increase the adsorption of reactants, and provide more molecules to the surface of semiconductors (He X. et al., 2017a; He X. et al., 2017b). Besides, some MOFs possess coordinatively unsaturated metal sites (or simply called open metal sites), which could act as sinks for charge carriers or electron donors for molecule activation (He X. and Wang W.N., 2018).

Therefore, numerous efforts have been made to design $\mathrm{MOF} /$ semiconductor composites, including UiO-66/ g- $\mathrm{C}_{3} \mathrm{~N}_{4}$ (UiO: University of Oslo) (Wang R. et al., 2015), $\mathrm{TiO}_{2}$ /ZIF-8 (ZIF: zeolitic imidazolate framework) (Liu Q. et al., 2017; Zeng X. et al., 2016), and $\mathrm{TiO}_{2} /$ HKUST-1 (Li R. et al., 2014; Wang H. et al., 2016). For instance, UiO-66/ g- $\mathrm{C}_{3} \mathrm{~N}_{4}$ composite photocatalyst was designed for hydrogen production, and the composite shows significant enhancement in the production rate than that of the counterparts (Wang R. et al., 2015). The enhancement is found to be attributed to the effective separation of photo-induced charge carriers at the interface. Liu et al. integrated ZIF-8 onto the mesoporous $\mathrm{TiO}_{2}$ nanobeads, and achieved pro- 


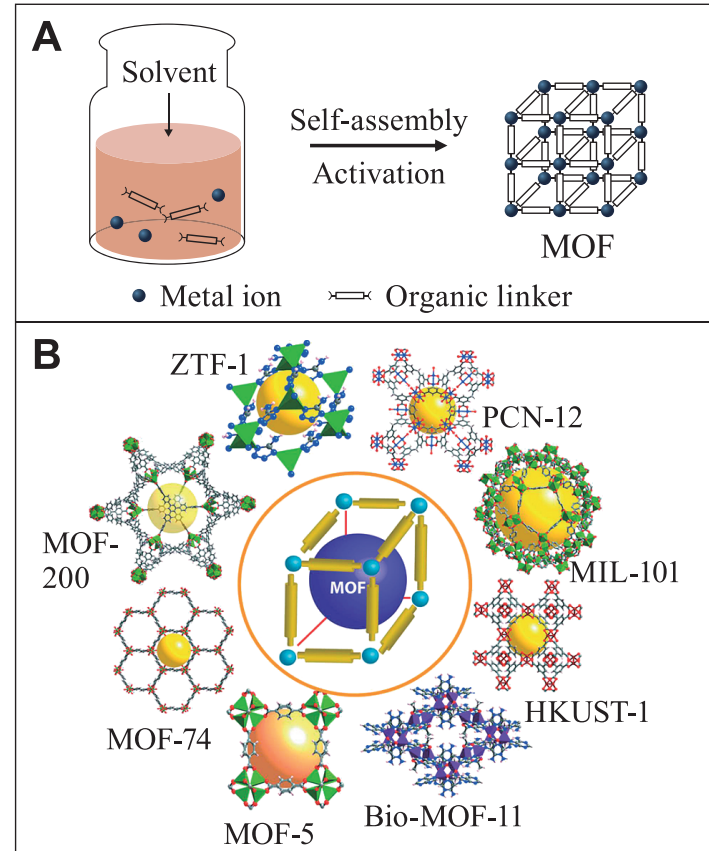

Fig. 8 (A) Conventional solvothermal synthesis of MOF structures. Reprinted with permission from Ref. (Lee Y.-R. et al., 2013). Copyright: (2013) Springer Nature. (B) Schematic representation of important reported MOFs which are known for high gas storage properties. Reprinted with permission from Ref. (Dey C. et al., 2014). Copyright: (2014) International Union of Crystallography.

moted performance for $\mathrm{Cr}(\mathrm{VI})$ reduction, which was attributed to not only the enhanced adsorption of $\mathrm{Cr}(\mathrm{VI})$, but also facilitated interfacial charge transfer (Liu Q. et al., 2017).

It should be noted that, the conventional synthesis of MOFs via wet-chemistry methods usually needs a long reaction duration, where the inefficient heat and mass transfer is inevitable. In this regard, the spray process is a promising alternate route for the rapid synthesis of MOFs (He X. et al., 2017a). As illustrated in Fig. 9, the rapid formation of MOFs within the microdroplets is primarily driven by the enhanced microscopic heat and mass transfer within the microdroplets. The theoretical calculations carried out by our group confirmed that the heat and mass transfer of the precursor within the microdroplets reaches equilibrium within milliseconds, which is much faster than that in bulk synthesis processes and benefits the subsequent nucleation and crystal growth ( $\mathrm{He} \mathrm{X}$. et al., 2017a). In addition to the synthesis of pristine MOFs, the spray-drying process was applied to tune the properties of these porous materials or design MOF/semiconductor composite (Garcia Marquez A. et al., 2013; Garzón-Tovar L. et al., 2017; He X. et al., 2017a). For example, the spray-drying strategy was applied to produce 14 different discrete nanoMOFs, where the production time and cost were drastically reduced (Carné-Sánchez A. et al., 2013).

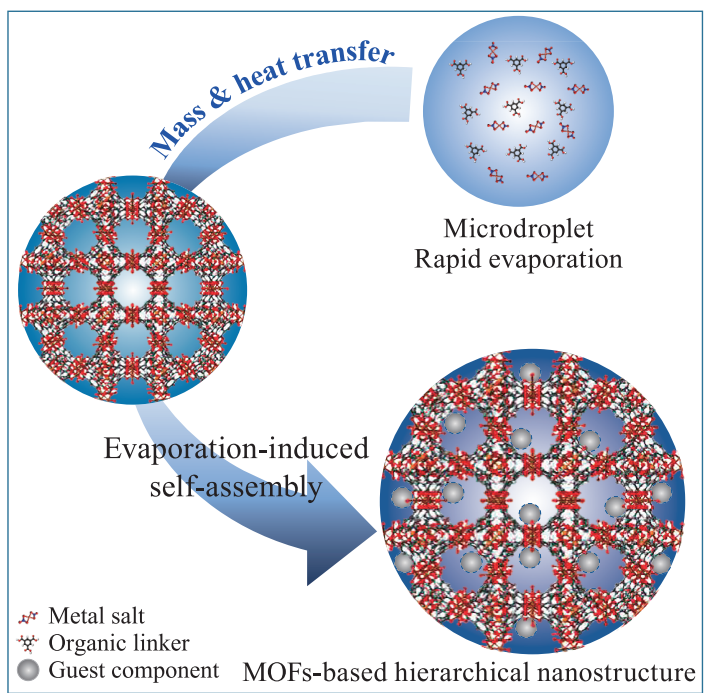

Fig. 9 Schematic illustration of the synthesis of MOFs-based hierarchical nanostructure via microdroplets. Reprinted with permission from Ref. (He X. et al., 2017a). Copyright: (2017) American Chemical Society.

Recently, $\mathrm{Cu}_{3}(\mathrm{TMA})_{2}$ (or HKUST-1, TMA stands for trimesic acid) and $\mathrm{TiO}_{2} / \mathrm{Cu}_{3}(\mathrm{TMA})_{2}$ (or $\mathrm{TiO}_{2} / \mathrm{HKUST}-1$,) composite photocatalyst were designed by our group through the spray process (Figs. 10A and B) (He X. et al., 2017a). The precursor components were mixed within the microdroplets after the liquid atomization, which ensured the homogeneous distribution of $\mathrm{TiO}_{2}$ in the matrix of HKUST-1 after the synthesis process (Fig. 10B). Besides, the incorporation of $\mathrm{TiO}_{2}$ did not affect the crystallinity of MOF. While, the temperature played an important role in the properties of the as-prepared $\mathrm{MOF} /$ semiconductor composite, including crystallinity and surface chemistry. To be specific, the increased temperature (up to $300{ }^{\circ} \mathrm{C}$ ) decreased the crystal size of the MOF due to the faster nucleation rate over growth rate. At higher temperatures $\left(>300^{\circ} \mathrm{C}\right)$, the MOF turned amorphous as a result of the disintegration of the organic ligand, which is consistent with the changes in the color of the MOF. The surface chemistry of the MOF synthesized at various temperatures was evaluated by using Fourier transform infrared spectroscopy (FT-IR). At low synthesis temperature, the MOF has similar functional groups as the organic ligand (i.e., TMA). The slight difference in the FT-IR peaks between MOF and the ligand was due to the deprotonation and subsequent coordination of the organic ligand with the metal ions. When the temperature exceeded $300^{\circ} \mathrm{C}$, the adsorption bands weakened or disappeared because of the decomposition of the framework, which was in a good agreement with XRD analysis. The as-prepared HKUST-1/ $/ \mathrm{TiO}_{2}$ composite was applied for $\mathrm{CO}_{2}$ photoreduction. The results revealed that HKUST-1 did not have the photocatalytic ability to reduce $\mathrm{CO}_{2}$ but acted as a major adsorbent to capture $\mathrm{CO}_{2}$ and $\mathrm{H}_{2} \mathrm{O}$ molecules 

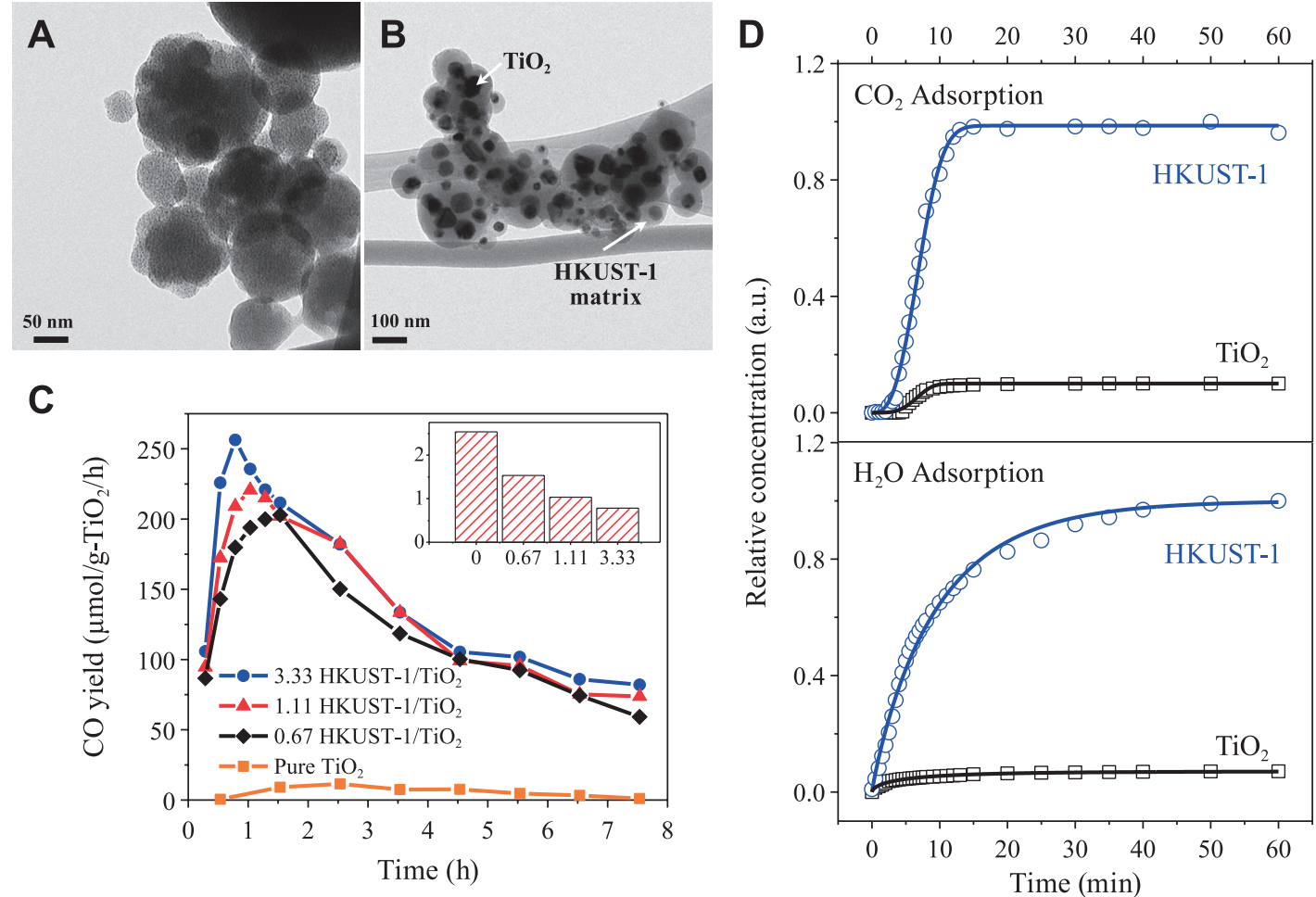

Fig. 10 TEM images of as-prepared (A) HKUST-1 and (B) HKUST-1/ $/ \mathrm{TiO}_{2} ;(\mathbf{C}) \mathrm{CO}_{2}$ photoreduction analysis; (D) $\mathrm{CO}_{2}$ and $\mathrm{H}_{2} \mathrm{O}$ adsorption analysis. Reprinted with permission from Ref. (He X. et al., 2017a). Copyright: (2017) American Chemical Society.

(Fig. 10D), which subsequently improved the reaction rate and the production yield (Fig. 10C).

\section{Conclusion and perspectives}

In summary, a comprehensive review of recent development of semiconductor-based photocatalysts (i.e., semiconductor heterojunction, $\mathrm{CGO} /$ semiconductor and $\mathrm{MOF} /$ semiconductor nanocomposites) within microdroplets was provided. As being highlighted, the microdroplet-based process features simple procedure and rapid synthesis rate. The basics of the spray processes were discussed, and typical examples of the as-prepared semiconductor-based composite and their photocatalytic performance were presented. Despite the huge progress in photocatalyst design via microdroplets, further exploration is still needed. Taking the synthesis of MOF/semiconductor composite for an example, formation of the MOFs with high-nuclearity second-building units typically requires a long reaction time, which is a challenge for the rapid spray process and should be addressed in the prospective development. In terms of this, some techniques, such as computational and combinatorial chemistry as well as machine learning-based synthesis, might offer key assistance in the future.

\section{Acknowledgements}

The Donors of the American Chemical Society Petroleum Research Fund (ACS-PRF) (No. 57072-DNI10), the National Science Foundation (No. CMMI-1727553), and the Virginia Commonwealth University (VCU) Presidential Research Quest Fund (PeRQ) are greatly acknowledged for their financial support.

\section{References}

Allen M.J., Tung V.C., Kaner R.B., Honeycomb carbon: a review of graphene, Chemical Reviews, 110 (2010) 132-145.

An X., Li K., Tang J., $\mathrm{Cu}_{2} \mathrm{O}$ /reduced graphene oxide composites for the photocatalytic conversion of $\mathrm{CO}_{2}$, ChemSusChem, 7 (2014) 1086-1093.

Arutanti O., Nandiyanto A.B.D., Ogi T., Iskandar F., Kim T.O., Okuyama K., Synthesis of composite $\mathrm{WO}_{3} / \mathrm{TiO}_{2}$ nanoparticles by flame-assisted spray pyrolysis and their photocatalytic activity, Journal of Alloys and Compounds, 591 (2014) 121-126.

Ashgriz N., Handbook of atomization and sprays: theory and applications, Springer Science \& Business Media, 2011, ISBN: 1441972641.

Boissiere C., Grosso D., Chaumonnot A., Nicole L., Sanchez C., Aerosol route to functional nanostructured inorganic and hybrid porous materials, Advanced Materials, 23 (2011) 
American Chemical Society, 139 (2017) 897-903.

Grbić B., Radić N., Stojadinović S., Vasilić R., Dohčević-Mitrović Z., Šaponjić Z., Stefanov P., $\mathrm{TiO}_{2} / \mathrm{WO}_{3}$ photocatalytic composite coatings prepared by spray pyrolysis, Surface and Coatings Technology, 258 (2014) 763-771.

Han S., Hu L., Liang Z., Wageh S., Al-Ghamdi A.A., Chen Y., Fang X., One-step hydrothermal synthesis of 2D hexagonal nanoplates of $\alpha-\mathrm{Fe}_{2} \mathrm{O}_{3} /$ graphene composites with enhanced photocatalytic activity, Advanced Functional Materials, 24 (2014) 5719-5727.

Haugen A.B., Kumakiri I., Simon C., Einarsrud M.-A., $\mathrm{TiO}_{2}$, $\mathrm{TiO}_{2} / \mathrm{Ag}$ and $\mathrm{TiO}_{2} / \mathrm{Au}$ photocatalysts prepared by spray pyrolysis, Journal of the European Ceramic Society, 31 (2011) 291-298.

He X., Gan Z., Fisenko S., Wang D., El-Kaderi H.M., Wang W.N., Rapid formation of metal-organic frameworks (MOFs) based nanocomposites in microdroplets and their applications for $\mathrm{CO}_{2}$ photoreduction, ACS Applied Materials \& Interfaces, 9 (2017a) 9688-9698.

He X., Wang W.N., MOF-based ternary nanocomposites for better $\mathrm{CO}_{2}$ photoreduction: roles of heterojunctions and coordinatively unsaturated metal sites, Journal of Materials Chemistry A, 6 (2018) 932-940.

He X., Yang C., Wang D., Gilliland Iii S.E., Chen D.-R., Wang W.N., Facile synthesis of ZnO@ZIF core-shell nanofibers: crystal growth and gas adsorption, CrystEngComm, 19 (2017b) 2445-2450.

He Z., Shi Y., Gao C., Wen L., Chen J., Song S., BiOCl/BiVO $\mathrm{p}-\mathrm{n}$ heterojunction with enhanced photocatalytic activity under visible-light irradiation, The Journal of Physical Chemistry C, 118 (2014) 389-398.

Hidayat D., Widiyastuti W., Ogi T., Okuyama K., Droplet generation and nanoparticle formation in low-pressure spray pyrolysis, Aerosol Science and Technology, 44 (2010) 692705.

Hinds W.C., Aerosol Technology: Properties, Behavior, and Measurement of Airborne Particles, John Wiley \& Sons, Inc., New York, 1999.

Hoffmann M.R., Martin S.T., Choi W., Bahnemann D.W., Environmental applications of semiconductor photocatalysis, Chemical Reviews, 95 (1995) 69-96.

Huang H., Han X., Li X., Wang S., Chu P.K., Zhang Y., Fabrication of multiple heterojunctions with tunable visible-lightactive photocatalytic reactivity in $\mathrm{BiOBr}-\mathrm{BiOI}$ full-range composites based on microstructure modulation and band structures, ACS Applied Materials \& Interfaces, 7 (2015) 482-492.

Huang L., Peng F., Wang H., Yu H., Li Z., Preparation and characterization of $\mathrm{Cu}_{2} \mathrm{O} / \mathrm{TiO}_{2}$ nano-nano heterostructure photocatalysts, Catalysis Communications, 10 (2009) 18391843.

Hummers Jr W.S., Offeman R.E., Preparation of graphitic oxide, Journal of the American Chemical Society, 80 (1958) 1339-1339.

Iskandar F., Gradon L., Okuyama K., Control of the morphology of nanostructured particles prepared by the spray drying of a nanoparticle sol, Journal of Colloid and Interface Science, 265 (2003) 296-303. 
Istândær.F., Kim S.-G., Nandiyanto A.B.D., Kaihatsu Y., Ogi T., WOkuyama K., Direct synthesis of hBN/MWCNT composite particles using spray pyrolysis, Journal of Alloys and Compounds, 471 (2009) 166-171.

Jia L., Wang D.-H., Huang Y.-X., Xu A.-W., Yu H.-Q., Highly durable n-doped graphene/CdS nanocomposites with enhanced photocatalytic hydrogen evolution from water under visible light irradiation, The Journal of Physical Chemistry C, 115 (2011) 11466-11473.

Jiang Y., Biswas P., Fortner J.D., A review of recent developments in graphene-enabled membranes for water treatment, Environmental Science: Water Research \& Technology, 2 (2016) 915-922.

Jiang Y., Wang W.N., Biswas P., Fortner J.D., Facile aerosol synthesis and characterization of ternary crumpled graphene- $\mathrm{TiO}_{2}-$ magnetite nanocomposites for advanced water treatment, ACS Applied Materials \& Interfaces, 6 (2014) 11766-11774.

Jin J., Yu J., Guo D., Cui C., Ho W., A hierarchical Z-scheme $\mathrm{CdS}-\mathrm{WO}_{3}$ photocatalyst with enhanced $\mathrm{CO}_{2}$ reduction activity, Small, 11 (2015) 5262-5271.

Kittel C., Introduction to Solid State Physics, John Wiley \& Sons, Inc., Hoboken, NJ, 2005.

Kumar N., Komarala V.K., Dutta V., In-situ synthesis of Au$\mathrm{CdS}$ plasmonic photocatalyst by continuous spray pyrolysis and its visible light photocatalysis, Chemical Engineering Journal, 236 (2014) 66-74.

Lee Y.-R., Kim J., Ahn W.-S., Synthesis of metal-organic frameworks: a mini review, Korean Journal of Chemical Engineering, 30 (2013) 1667-1680.

Li C., Ming T., Wang J., Wang J., Yu J.C., Yu S.-h., Ultrasonic aerosol spray-assisted preparation of $\mathrm{TiO}_{2} / \mathrm{In}_{2} \mathrm{O}_{3}$ composite for visible-light-driven photocatalysis, Journal of Catalysis, 310 (2014) 84-90.

Li N., Liu G., Zhen C., Li F., Zhang L., Cheng H.M., Battery performance and photocatalytic activity of mesoporous anatase tio $_{2}$ nanospheres/graphene composites by templatefree self-assembly, Advanced Functional Materials, 21 (2011) 1717-1722.

Li Q., Guo B., Yu J., Ran J., Zhang B., Yan H., Gong J.R., Highly efficient visible-light-driven photocatalytic hydrogen production of CdS-cluster-decorated graphene nanosheets, Journal of the American Chemical Society, 133 (2011) 10878-10884.

Li R., Hu J., Deng M., Wang H., Wang X., Hu Y., Jiang H.-L., Jiang J., Zhang Q., Xie Y., Xiong Y., Integration of an inorganic semiconductor with a metal-organic framework: a platform for enhanced gaseous photocatalytic reactions, Advanced Materials, 26 (2014) 4783-4788.

Liang Y., Wang H., Sanchez Casalongue H., Chen Z., Dai H., $\mathrm{TiO}_{2}$ nanocrystals grown on graphene as advanced photocatalytic hybrid materials, Nano Research, 3 (2010) 701705.

Linsebigler A.L., Lu G.Q., Yates J.T., Photocatalysis on $\mathrm{TiO}_{2}$ surfaces_principles, mechanisms, and selected results, Chemical Reviews, 95 (1995) 735-758.

Liu Q., Zhou B., Xu M., Mao G., Integration of nanosized ZIF-8 particles onto mesoporous $\mathrm{TiO}_{2}$ nanobeads for enhanced photocatalytic activity, RSC Advances, 7 (2017) 8004-8010.

Low J., Yu J., Jaroniec M., Wageh S., Al-Ghamdi A.A., Heterojunction photocatalysts, Advanced Materials, 29 (2017) 1601694. DOI:10.1002/adma.201601694

Lu Y.F., Fan H.Y., Stump A., Ward T.L., Rieker T., Brinker C.J., Aerosol-assisted self-assembly of mesostructured spherical nanoparticles, Nature, 398 (1999) 223-226.

Luo J., Jang H.D., Sun T., Xiao L., He Z., Katsoulidis A.P., Kanatzidis M.G., Gibson J.M., Huang J., Compression and aggregation-resistant particles of crumpled soft sheets, ACS Nano, 5 (2011) 8943-8949.

Ma X., Zachariah M.R., Zangmeister C.D., Crumpled nanopaper from graphene oxide, Nano Letters, 12 (2012) 486-489.

Ma X., Zachariah M.R., Zangmeister C.D., Reduction of suspended graphene oxide single sheet nanopaper: the effect of crumpling, The Journal of Physical Chemistry C, 117 (2013) 3185-3191.

Mao B.S., Wen Z., Bo Z., Chang J., Huang X., Chen J., Hierarchical nanohybrids with porous CNT-networks decorated crumpled graphene balls for supercapacitors, ACS Applied Materials \& Interfaces, 6 (2014) 9881-9889.

Mao S., Wen Z., Huang T., Hou Y., Chen J., High-performance bifunctional electrocatalysts of 3D crumpled graphene-cobalt oxide nanohybrids for oxygen reduction and evolution reactions, Energy \& Environmental Science, 7 (2014) 609-616.

Mao S., Wen Z., Kim H., Lu G., Hurley P., Chen J., A general approach to one-pot fabrication of crumpled graphenebased nanohybrids for energy applications, ACS Nano, 6 (2012) 7505-7513.

Min S., Lu G., Sites for high efficient photocatalytic hydrogen evolution on a limited-layered $\mathrm{MoS}_{2}$ cocatalyst confined on graphene sheets - the role of graphene, The Journal of Physical Chemistry C, 116 (2012) 25415-25424.

Nandiyanto A.B.D., Iskandar F., Okuyama K., Nanosized polymer particle-facilitated preparation of mesoporous silica particles using a spray method, Chemistry Letters, 37 (2008) 1040-1041.

Ng Y.H., Iwase A., Kudo A., Amal R., Reducing graphene oxide on a visible-light $\mathrm{BiVO}_{4}$ photocatalyst for an enhanced photoelectrochemical water splitting, The Journal of Physical Chemistry Letters, 1 (2010) 2607-2612.

Nie Y., Wang W.N., Jiang Y., Fortner J., Biswas P., Crumpled reduced graphene oxide-amine-titanium dioxide nanocomposites for simultaneous carbon dioxide adsorption and photoreduction, Catalysis Science \& Technology, 6 (2016) 6187-6196.

Novoselov K.S., Geim A.K., Morozov S.V., Jiang D., Zhang Y., Dubonos S.V., Grigorieva I.V., Firsov A.A., Electric field effect in atomically thin carbon films, Science, 306 (2004) 666-669.

Oh W.-C., Chen M., Cho K., Kim C., Meng Z., Zhu L., Synthesis of graphene-CdSe composite by a simple hydrothermal method and its photocatalytic degradation of organic dyes, Chinese Journal of Catalysis, 32 (2011) 1577-1583.

Okuyama K., Wuled Lenggoro I., Preparation of nanoparticles via spray route, Chemical Engineering Science, 58 (2003) 537-547.

Pan X., Zhao Y., Liu S., Korzeniewski C.L., Wang S., Fan Z., 
Pawinrat P., Mekasuwandumrong O., Panpranot J., Synthesis of $\mathrm{Au}-\mathrm{ZnO}$ and $\mathrm{Pt}-\mathrm{ZnO}$ nanocomposites by one-step flame spray pyrolysis and its application for photocatalytic degradation of dyes, Catalysis Communications, 10 (2009) 13801385.

Perera S.D., Mariano R.G., Vu K., Nour N., Seitz O., Chabal Y., Balkus K.J., Hydrothermal synthesis of graphene- $\mathrm{TiO}_{2}$ nanotube composites with enhanced photocatalytic activity, ACS Catalysis, 2 (2012) 949-956.

Qu Y., Duan X., Progress, challenge and perspective of heterogeneous photocatalysts, Chemical Society Reviews, 42 (2013) 2568-2580.

Schneider J., Matsuoka M., Takeuchi M., Zhang J., Horiuchi Y., Anpo M., Bahnemann D.W., Understanding $\mathrm{TiO}_{2}$ photocatalysis: mechanisms and materials, Chemical Reviews, 114 (2014) 9919-9986.

Somorjai G.A., Li Y., Introduction to Surface Chemistry and Catalysis, Wiley, New York, 2010.

Stankovich S., Dikin D.A., Dommett G.H.B., Kohlhaas K.M., Zimney E.J., Stach E.A., Piner R.D., Nguyen S.T., Ruoff R.S., Graphene-based composite materials, Nature, 442 (2006) 282-286.

Sun Y., Qu B., Liu Q., Gao S., Yan Z., Yan W., Pan B., Wei S., Xie Y., Highly efficient visible-light-driven photocatalytic activities in synthetic ordered monoclinic $\mathrm{BiVO}_{4}$ quantum tubes-graphene nanocomposites, Nanoscale, 4 (2012) 37613767.

Teoh W.Y., Mädler L., Beydoun D., Pratsinis S.E., Amal R., Direct (one-step) synthesis of $\mathrm{TiO}_{2}$ and $\mathrm{Pt} / \mathrm{TiO}_{2}$ nanoparticles for photocatalytic mineralisation of sucrose, Chemical Engineering Science, 60 (2005) 5852-5861.

Tian Y., Zhao C.Y., A review of solar collectors and thermal energy storage in solar thermal applications, Applied Energy, 104 (2013) 538-553.

Tran P.D., Batabyal S.K., Pramana S.S., Barber J., Wong L.H., Loo S.C.J., A cuprous oxide-reduced graphene oxide $\left(\mathrm{Cu}_{2} \mathrm{O}-\mathrm{rGO}\right)$ composite photocatalyst for hydrogen generation: employing rGO as an electron acceptor to enhance the photocatalytic activity and stability of $\mathrm{Cu}_{2} \mathrm{O}$, Nanoscale, 4 (2012) 3875-3878.

Wang D., Li Z., Zhou J., Fang H., He X., Jena P., Zeng J.-B., Wang W.N., Simultaneous detection and removal of formaldehyde at room temperature: Janus Au@ZnO@ZIF-8 Nanoparticles, Nano-Micro Letters, 10 (2018) 4(11pp).

Wang D., Pillai S.C., Ho S.-H., Zeng J., Li Y., Dionysiou D.D., Plasmonic-based nanomaterials for environmental remediation, Applied Catalysis B: Environmental, 237 (2018) 721741.

Wang H., Yu T., Tan X., Zhang H., Li P., Liu H., Shi L., Li X., Ye J., Enhanced photocatalytic oxidation of isopropanol by HKUST-1@TiO 2 core-shell structure with ultrathin anatase porous shell: toxic intermediate control, Industrial \& Engineering Chemistry Research, 55 (2016) 8096-8103.

Wang H., Zhang L., Chen Z., Hu J., Li S., Wang Z., Liu J., Wang $\mathrm{X}$., Semiconductor heterojunction photocatalysts: design,

construction, and photocatalytic performances, Chemical Society Reviews, 43 (2014) 5234-5244.

Wang J.-C., Zhang L., Fang W.-X., Ren J., Li Y.-Y., Yao H.-C., Wang J.-S., Li Z.-J., Enhanced photoreduction $\mathrm{CO}_{2}$ activity over direct $\mathrm{Z}$-scheme $\alpha$ - $\mathrm{Fe}_{2} \mathrm{O}_{3} / \mathrm{Cu}_{2} \mathrm{O}$ heterostructures under visible light irradiation, ACS Applied Materials \& Interfaces, 7 (2015) 8631-8639.

Wang R., Gu L., Zhou J., Liu X., Teng F., Li C., Shen Y., Yuan Y., Quasi-polymeric metal-organic framework UiO$66 / \mathrm{g}-\mathrm{C}_{3} \mathrm{~N}_{4}$ heterojunctions for enhanced photocatalytic hydrogen evolution under visible light irradiation, Advanced Materials Interfaces, 2 (2015) 1500037(5pp). DOI: $10.1002 /$ admi.201500037

Wang W.N., He X., Aerosol processing of crumpled graphene oxide-based nanocomposites for drug delivery, Current Pharmaceutical Design, 22 (2016) 2491-2500.

Wang W.N., Jiang Y., Biswas P., Evaporation-induced crumpling of graphene oxide nanosheets in aerosolized droplets: confinement force relationship, The Journal of Physical Chemistry Letters, 3 (2012) 3228-3233.

Wang W.N., Jiang Y., Fortner J.D., Biswas P., Nanostructured graphene-titanium dioxide composites synthesized by a single-step aerosol process for photoreduction of carbon dioxide, Environmental Engineering Science, 31 (2014) 428-434.

Wang W.N., Purwanto A., Lenggoro I.W., Okuyama K., Chang H., Jang H.D., Investigation on the correlations between droplet and particle size distribution in ultrasonic spray pyrolysis, Industrial \& Engineering Chemistry Research, 47 (2008) 1650-1659.

Wang W.N., Tarafdar J.C., Biswas P., Nanoparticle synthesis and delivery by an aerosol route for watermelon plant foliar uptake, Journal of Nanoparticle Research, 15 (2013) 1417(13pp). DOI: 10.1007/s11051-013-1417-8

Wang W.N., Widiyastuti W., Lenggoro I.W., Kim T.O., Okuyama K., Photoluminescence optimization of luminescent nanocomposites fabricated by spray pyrolysis of a colloid-solution precursor, Journal of the Electrochemical Society, 154 (2007) J121-J128.

Wang W.N., Wu F., Myung Y., Niedzwiedzki D.M., Im H.S., Park J., Banerjee P., Biswas P., Surface engineered $\mathrm{CuO}$ nanowires with $\mathrm{ZnO}$ islands for $\mathrm{CO}_{2}$ photoreduction, ACS Applied Materials \& Interfaces, 7 (2015) 5685-5692.

Wang W.N., Itoh Y., Lenggoro I.W., Okuyama K., Nickel and nickel oxide nanoparticles prepared from nickel nitrate hexahydrate by a low pressure spray pyrolysis, Materials Science and Engineering B-Solid State Materials for Advanced Technology, 111 (2004) 69-76.

Wang W.N., Lenggoro I.W., Okuyama K., Preparation of nanoparticles by spray routes, in: Nalwa H.S. (Ed.) Encyclopedia of Nanoscience and Nanotechnology, American Scientific Publishers, 2011a, pp. 435-458.

Wang W.N., Park J., Biswas P., Rapid synthesis of nanostructured $\mathrm{Cu}-\mathrm{TiO}_{2}-\mathrm{SiO}_{2}$ composites for $\mathrm{CO}_{2}$ photoreduction by evaporation driven self-assembly, Catalysis Science \& Technology, 1 (2011b) 593-600.

Wang W.N., Purwanto A., Okuyama K., Low-pressure spray pyrolysis, in: Ashgriz N. (Ed.) Handbook of Atomization 
Zangmeister C.D., Ma X., Zachariah M.R., Restructuring of graphene oxide sheets into monodisperse nanospheres, Chemistry of Materials, 24 (2012) 2554-2557.

Widiyandari H., Purwanto A., Balgis R., Ogi T., Okuyama K., $\mathrm{CuO} / \mathrm{WO}_{3}$ and $\mathrm{Pt} / \mathrm{WO}_{3}$ nanocatalysts for efficient pollutant degradation using visible light irradiation, Chemical Engineering Journal, 180 (2012) 323-329.

Xiang Q., Yu J., Jaroniec M., Preparation and enhanced visiblelight photocatalytic $\mathrm{H}_{2}$-production activity of graphene/ $\mathrm{C}_{3} \mathrm{~N}_{4}$ composites, The Journal of Physical Chemistry C, 115 (2011) 7355-7363.

Xiong Y., Kodas T.T., Droplet evaporation and solute precipitation during spray pyrolysis, Journal of Aerosol Science, 24 (1993) 893-908.

Xiong Z., Lei Z., Xu Z., Chen X., Gong B., Zhao Y., Zhao H., Zhang J., Zheng C., Flame spray pyrolysis synthesized $\mathrm{ZnO} / \mathrm{CeO}_{2}$ nanocomposites for enhanced $\mathrm{CO}_{2}$ photocatalytic reduction under UV-Vis light irradiation, Journal of $\mathrm{CO}_{2}$ Utilization, 18 (2017) 53-61.

Xu H., Xu Y., Li H., Xia J., Xiong J., Yin S., Huang C., Wan H., Synthesis, characterization and photocatalytic property of $\mathrm{AgBr} / \mathrm{BiPO}_{4}$ heterojunction photocatalyst, Dalton Transactions, 41 (2012) 3387-3394.

Yang J., Zhang X., Liu H., Wang C., Liu S., Sun P., Wang L., Liu Y., Heterostructured $\mathrm{TiO}_{2} / \mathrm{WO}_{3}$ porous microspheres: preparation, characterization and photocatalytic properties, Catalysis Today, 201 (2013) 195-202.

Yang M.-Q., Zhang N., Pagliaro M., Xu Y.-J., Artificial photosynthesis over graphene-semiconductor composites. Are we getting better?, Chemical Society Reviews, 43 (2014) $8240-8254$.

Zeng X., Huang L., Wang C., Wang J., Li J., Luo X., Sonocrystallization of ZIF-8 on electrostatic spinning $\mathrm{TiO}_{2}$ nanofibers surface with enhanced photocatalysis property through synergistic effect, ACS Applied Materials \& Interfaces, 8 (2016) 20274-20282.

Zhang D., Hu B., Guan D., Luo Z., Essential roles of defects in pure graphene $/ \mathrm{Cu}_{2} \mathrm{O}$ photocatalyst, Catalysis Communications, 76 (2016) 7-12.

Zhang Y., Tang Z.-R., Fu X., Xu Y.-J., Engineering the unique $2 \mathrm{D}$ mat of graphene to achieve graphene- $\mathrm{TiO}_{2}$ nanocomposite for photocatalytic selective transformation: what advantage does graphene have over its forebear carbon nanotube?, ACS Nano, 5 (2011) 7426-7435.

Zhao C., Krall A., Zhao H., Zhang Q., Li Y., Ultrasonic spray pyrolysis synthesis of $\mathrm{Ag} / \mathrm{TiO}_{2}$ nanocomposite photocatalysts for simultaneous $\mathrm{H}_{2}$ production and $\mathrm{CO}_{2}$ reduction, International Journal of Hydrogen Energy, 37 (2012) 99679976.

Zhou H., Qu Y., Zeid T., Duan X., Towards highly efficient photocatalysts using semiconductor nanoarchitectures, Energy \& Environmental Science, 5 (2012) 6732-6743.

Zou W., Zhang L., Liu L., Wang X., Sun J., Wu S., Deng Y., Tang C., Gao F., Dong L., Engineering the $\mathrm{Cu}_{2} \mathrm{O}-$ reduced graphene oxide interface to enhance photocatalytic degradation of organic pollutants under visible light, Applied Catalysis B: Environmental, 181 (2016) 495-503.

\section{Authors' Short Biographies}

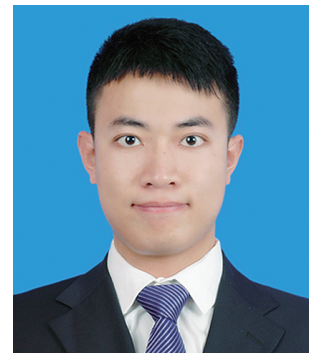

\section{Xiang He}

Xiang He is a Ph.D. candidate in the Department of Mechanical and Nuclear Engineering at Virginia Commonwealth University, USA, under the supervision of Prof. WeiNing Wang since Fall 2015. He received his Master's and Bachelor's degrees in Environmental Engineering from Sun Yat-sen University, China, in 2015 and 2013, respectively. His research is focusing on the rational design of efficient photocatalysts for energy and environmental applications.

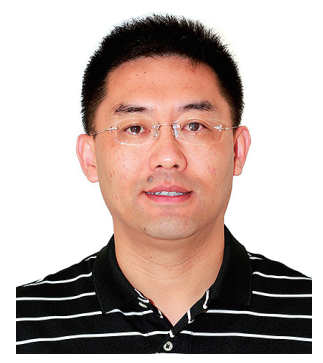

\section{Wei-Ning Wang}

Wei-Ning Wang is an Assistant Professor in the Department of Mechanical and Nuclear Engineering at Virginia Commonwealth University. He received Ph.D. degree in Chemistry and Chemical Engineering from Hiroshima University in 2006, and worked as a JSPS postdoctoral fellow from 2006 to 2007. He became an Assistant Professor at the same university from 2007 to 2009. He was a Postdoctoral Research Associate at Washington University in St. Louis from 2009 till 2012 and became Research Assistant Professor from 2013 to 2014. His research concerns functional materials design, synthesis and characterization, and their applications to address energy and environmental issues. 